\title{
Migração no Semiárido Setentrional: Dinâmica Recente, Retorno e
} Políticas Sociais ${ }^{1}$

Migration in the Northern Semi-Arid: Recent Dynamics, Return and Social

\author{
Ricardo Ojima ${ }^{2}$ \\ Wilson Fusco ${ }^{3}$
}

\section{INTRODUÇÃO}

O semiárido setentrional, também conhecido como "sertão norte", considera todos os municípios oficialmente incluídos no semiárido, segundo a definição prevista na Portaria $\mathrm{n}^{\mathrm{o}}$ 89 do Ministério da Integração Nacional, mas que se situam na porção setentrional do leito do Rio São Francisco. Assim, são os municípios do semiárido oficial incluídos nos estados do Piauí, Ceará, Rio Grande do Norte, Paraíba, Pernambuco e Alagoas (ver FIG. 1). Esse recorte inclui um total de 754 municípios de um total de 1.134 que constituem o semiárido, correspondentes a 66,5\% dos municípios. Viviam nessa região 14,1 milhões de habitantes, segundo dados do Censo Demográfico 2010 e é a região do semiárido que contém o maior número de divisões político-administrativas tanto em termos de municípios quanto em termos de Unidades da Federação.

É também a região onde se identifica a maior incidência de estiagens, o que coloca a população que vive nessa região em grande risco potencial da ocorrência de desastres naturais dessa natureza. Trata-se de uma região semiárida com precipitações entre 200 e $800 \mathrm{~mm}$ anuais, mas com chuvas distribuídas de maneira irregular e com evaporação até três vezes maior do que a precipitação.

\footnotetext{
${ }^{1}$ Este trabalho foi desenvolvido no âmbito dos projetos: "Impacto dos Programas de Transferência de Renda sobre a Dinâmica Populacional e Redução da Pobreza no Semiárido Setentrional Nordestino" (CNPq, processo: 457110/2013-9), "Migração e políticas sociais no semiárido setentrional: características sociodemográficas e fatores de atração/retenção" (CNPq, processos: 471968/2014-5 e 444798/2014-5) e "Urbanização, condições de vida e mobilidade espacial da população no contexto dos biomas nordestinos: repensando as heterogeneidades intra-regionais" (CNPq, processo: 403853/2012-5). Observatório das Migrações Nordestinas.

${ }^{2}$ Professor Adjunto, Sociólogo e Doutor em Demografia. Depto de Demografia e Ciências Atuariais (DDCA). Universidade Federal do Rio Grande do Norte (UFRN). E-mail: < ricardo.ojima@ gmail.com>.

${ }^{3}$ Pesquisador Associado, Sociólogo e Doutor em Demografia. Fundaj/Dipes/Coordenação Geral de Estudos Econômicos e Populacionais (CGEP). Fundação Joaquim Nabuco (Fundaj). E-mail: <wilson.fusco67@gmail.com>.
} 


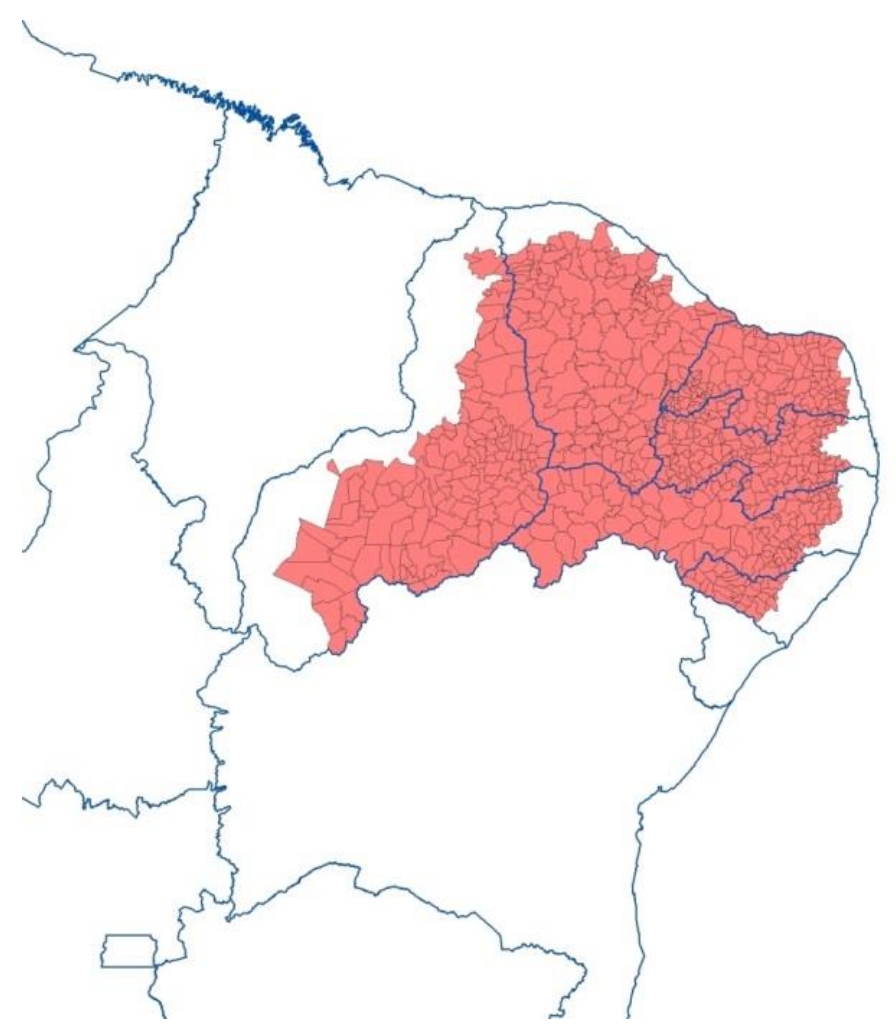

FIGURA 1 - Municípios do semiárido setentrional Fonte: IBGE, Malha Digital Municipal

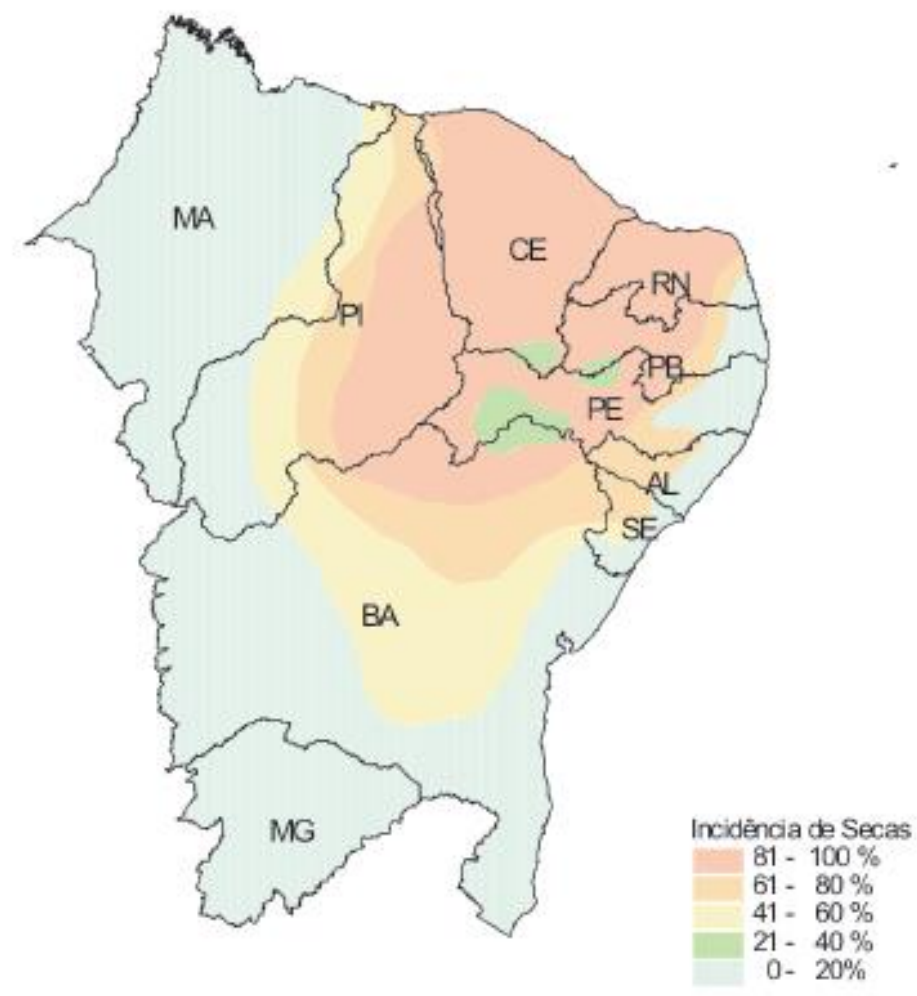

FIGURA 2 - Incidência de secas no semiárido

Fonte: Min. da Integração Nacional, Plano Estratégico de Desenvolvimento Sustentável do Semiárido, 2005 
A região do semiárido brasileiro é tradicionalmente considerada por muitos a própria expressão das desigualdades regionais e, de certa maneira, torna-se o estereótipo nordestino como um todo. |Contexto demográfico de estagnação, o semiárido setentrional apresentou, nas décadas de 1970 e 1980, taxas de crescimento populacional (1,38\% a.a. e 1,00\% a.a., respectivamente) mais baixas do que o semiárido como um todo (1,49\% a.a. e 1,28\% a.a.). Em comparação com o Nordeste como um todo a diferença é muito mais expressiva $(2,52 \%$ a.a. e 2,15\% a.a.), indicando que houve uma desconcentração da população nordestina do semiárido e mais significativa na sua porção setentrional.

Assim, apesar de esforços de políticas públicas anteriores, a região do semiárido se consolidou em uma região de expulsão da população. Se em 1970 a população do semiárido setentrional representava $32,5 \%$ da população Nordestina e $54,6 \%$ das UFs que têm seus territórios incluídos no semiárido, em 2010 essa participação reduziu-se para 26,7\% e 46,6\%, respectivamente. De fato, desde a criação da Superintendência de Desenvolvimento do Nordeste (SUDENE) em 1959, a dimensão demográfica se colocava como um desafio a ser enfrentado. Ou seja, como apontado por Furtado (1959), a densidade demográfica do semiárido seria incompatível com o desenvolvimento econômico da região (Cf. Ojima, 2013) e políticas de desconcentração da população foram incentivadas nesse período. Mesmo assim podemos perceber que o semiárido não é um vazio populacional,

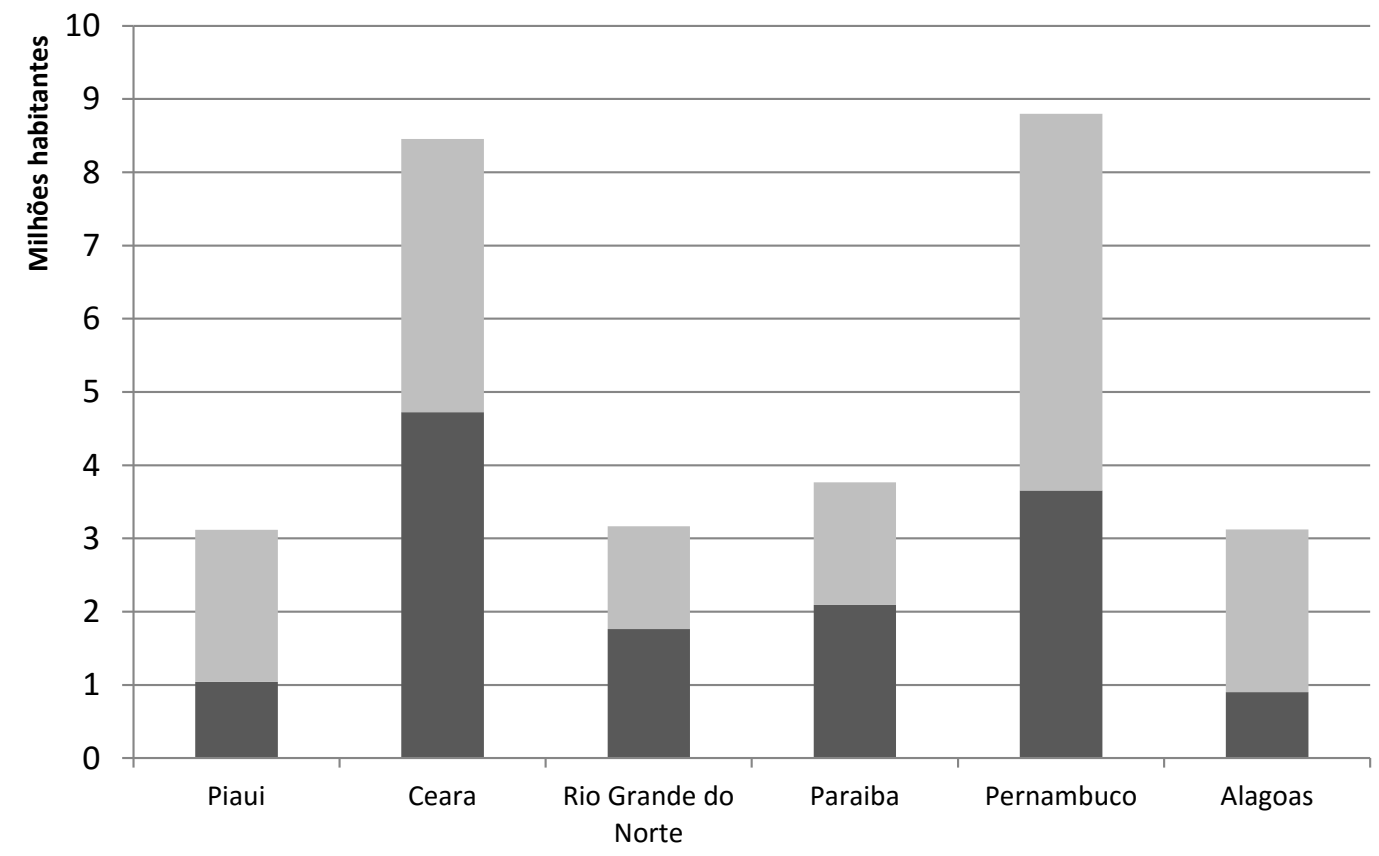

Não Semiárido Semiárido

FIGURA 3 - Distribuição da população total segundo Unidades da Federação e subdivisões do Semiárido Setentrional e Demais municípios

Fonte: IBGE, Censo Demográfico 2010 
Ceará e Pernambuco são as UFs com maior contingente populacional das seis UFs do semiárido setentrional. Entretanto, a despeito da grande extensão territorial do semiárido na área total de cada UF (ver FIG 1), a participação da população tende a ser equilibrada entre as duas subdivisões. No Ceará, Rio Grande do Norte e Paraíba, a participação da população do semiárido é da ordem de 55\%, enquanto que nas demais UFs essa proporção é sempre menor. Portanto, ainda nos dias de hoje se confirma evidências de que seja "uma das regiões semiáridas mais povoadas existentes no planeta" (Ab’Saber, 1999, p.7).

Neste contexto, entender o estado atual da dinâmica migratória neste recorte territorial se constitui como um importante elemento a ser considerado para entender o impacto recente das políticas públicas diretas e indiretas para o enfrentamento da condição secular de vulnerabilidade do semiárido setentrional. As estratégias de "convivência" com às secas preconizadas mais recentemente, em contraste com aquelas de "combate", podem ter contribuído para mudanças nesse contexto. São poucos os estudos que analisam a dinâmica demográfica a partir de um recorte socioambiental (Cf. Ojima; Martine, 2012) e mais reduzidos ainda aqueles que tenham como foco o detalhamento da análise dos fluxos migratórios das regiões de evasão populacional.

Assim, o objetivo deste artigo é desenvolver uma caracterização da dinâmica demográfica, com ênfase nos aspectos migratórios do semiárido setentrional. Para essa caracterização, primeiro será contextualizada brevemente a situação de algumas politicas sociais recentes e seus principais impactos sobre a dinâmica demográfica para, posteriormente, identificar as especificidades da região nos aspectos migratórios. Finalmente, em um esforço de síntese, são apontadas algumas evidências da importância das políticas sociais no contexto do semiárido setentrional.

\section{O CONTEXTO DAS POLÍTICAS SOCIAIS}

Segundo Rios-Neto, Martine e Alves (2009), a universalização das políticas sociais proposta pela Constituição de 1988 se fundamentou em uma busca pela "desmercantilização" das políticas assistenciais não contributivas que, de certa forma, contribuiu para que se reduzisse a tendência meritocrática-particularista que favoreciam o acirramento de desigualdades sociais sob um modelo em que os critérios de elegibilidade das políticas demandavam a participação do indivíduo na constituição do próprio sistema de seguridade (Cf. Medeiros, 2009; Draibe, 1989). Segundo Ipea (2010), os últimos anos do século 20 mostraram significativa redução das desigualdades sociais no Brasil, sobretudo, na primeira década dos anos 2000, com uma redução de cerca de 5 pontos no coeficiente de Gini. 
Para Silva, Yazbek e Giovanni (2012, p. 18) todas as sociedades possuem algum mecanísmo de proteção social, mas o que a define em sociedades complexas, como a nossa, é o seu elevado grau de institucionalização, configurando assim um importante mecanísmo de divisão social do trabalho e da economia. As políticas de transferência de renda no Brasil ganharam destaque não apenas pela sua importante expansão nos primeiros anos do século 21, mas, sobretudo pela controvérsia engendrada pelos diversos interesses em disputa dentro do debate político. Dentro deste contexto, os aspectos demográficos que cercam a demanda por políticas sociais passaram a ser discutidos para além de uma abordagem neomalthusiana e cada vez mais incorporou-se debates sobre a transição da estrutura etária, o processo de envelhecimento populacional, as reconfigurações nos fluxos migratórios e outros. Assim, a "questão populacional" deixa de ser resumida na mera análise do crescimento e passa a ganhar contornos mais sinuosos no que se refere aos desafios para o entendimento das relações entre população, políticas sociais e desenvolvimento (Cf. Rios-Neto; Martine, Alves, 2009).

Entre as políticas de desenvolvimento social e combate a fome que se destacam no contexto nacional, programas como o Bolsa Família (PBF) e o Benefício de Prestação Continuada (BPC), se somam aos benefícios da Previdência Social e passam a ter papel importante no cenário de políticas sociais brasileiras, sobretudo nas regiões mais carentes e de baixo dinamismo econômica, como é o caso da região do semiárido setentrional. Mas é no PBF que se concentram as mais importantes críticas e controvérsias, pois quando os benefícios são focalizados nos grupos de idade de idosos, tendem a ser percebidos pela opinião pública como retorno legítimo e justo por contribuição social e econômica pretérita (Cf. Rios-Neto; Martine, Alves, 2009). Ou seja, o desenho de focalização proposto no PBF resgata, para alguns, a percepção do assistencialismo que gera dependência e incentiva a natalidade.

Talvez o aspecto demográfico mais evidente na relação com o PBF seja a percepção de que o desenho da política seja pró-natalista, através da transferência condicionada às famílias com crianças em idade escolar. Assim, vincular o recebimento de benefícios sociais à quantidade de filhos, tenderia a incentivar que os mais pobres tenham mais filhos para garantir maiores retornos pecuniários. Entretanto, o aspecto pouco explorado no desenho da política é o objetivo de médio e longo prazo de romper com o ciclo da pobreza através da garantia do exercício de cidadania por meio do acesso à escolarização e saúde das novas gerações (Cf. Alves; Cavenaghi, 2009). 
De fato, a focalização do programa parece atender aos seus objetivos primários, possibilitando maiores gastos com alimentação, vestuários e educação infantil, aliviando significativamente a situação de extrema pobreza, mas indiretamente também garantem maiores condições de reprodução social (Cf. Cedeplar, 2007; Alves; Cavenaghi, 2009) e, consequentemente, aumentariam as chances de romper com o ciclo da pobreza e até mesmo trazer efeitos indiretos de redução das taxas de fecundidade (Cf. Rios-Neto; Martine, Alves, 2009).

Os impactos indiretos na economia local e no desenvolvimento social são percebidos juntamente com o acionamento de mecanísmos de crédito local. Ou seja, com o ingresso no $\mathrm{PBF}$, os beneficiários passaram a contar com acesso à crédito juntos aos comerciantes locais (Cf. Weissheimer, 2010; Rego; Pinzani, 2013), o que favorece a redução das vulnerabilidades sociais através da criação de mecanísmos de mercantilização das redes de proteção da reprodução social imediata.

Nesse aspecto, outro componente demográfico que surge e ainda é muito pouco explorado é a relação entre o impacto dos programas de transferência de renda e os processos migratórios. Rego e Pinzani (2013) relatam o discurso de beneficiários do PBF que abandonaram o projeto de emigração de regiões de empobrecidas do semiárido nordestino devido à melhoria das condições de permanência posteriores ao recebimento do benefício. Assim, mesmo com a progressiva redução dos obstáculos intervenientes (como a maior mobilidade, por exemplo) encontrados entre essas regiões e os principais centros urbanos do país ao longo das últimas décadas, a redução dos fatores de expulsão através da redução da extrema pobreza e da dinamização econômica local parecem ter contribuido para que a população deixasse de migrar.

Há ainda a possibilidade de que tais políticas, assim como já identificado pela literatura no que se refere à previdência social, favoreçam o retorno migratório de uma parcela da população que outrora se viu constrangida a emigrar do semiárido setentrional (Cf. Campos; Barbieri; Carvalho, 2008; Oliver, 2008). Assim, tal qual o benefício da aposentadoria, o PBF pode constituir-se em um mecanísmo de estímulo ao retorno migratório (e indiretamente à imigração direta), pois permite que o beneficiário de políticas sociais busque um local de residência que reduza seu custo de vida, retorne ao grupo familiar expandido ou simplesmente escolham residir em regiões mais tranquilas para um determinado estilo de vida.

Neste contexto de transformações recentes, a região do semiárido setentrional é particularmente impactada, pois a participação relativa do valor adicionado bruto das atividades de "Administração, saúde e educação públicas e seguridade social" na economia de 
$89 \%$ dos municípios da região representa mais de 1/3 do PIB municipal (IBGE, 2011). Ou seja, há uma grande participação de recursos provenientes de atividades ligadas aos serviços públicos, empregos públicos e transferências de renda. Em Areia de Baraúnas e Poço Dantas, ambos no semiárido paraibano, essa participação chega a mais de 70\% do PIB municipal. Em termos da sua evolução, essa participação aumentou entre 2000 e 2010 entre os municípios do semiárido setentrional, passando de 30,1\% para 33,2\%. Assim, a década de 2000 refletiu nos municípios do semiárido setentrional um aumento da quantidade de municípios com maior dependência da "máquina pública", pois os municípios com mais de 1/3 do valor adicionado bruto nas atividades públicas representava $81 \%$ dos 754 municípios da região.

Somado a isso, segundo os dados do Censo Demográfico 2010, a participação de trabalhadores sem carteira de trabalho assinada entre os municípios do semiárido setentrional era maior do que nos demais municípios das suas UFs. Com 36,6\% das pessoas com 10 anos e mais nessa categoria, o semiárido setentrional se destaca em relação aos demais municípios das UFs (com 25,2\%) e mais ainda se comparado aos demais municípios do Brasil (19,7\%).

Trata-se de uma "região sob intervenção, onde o planejamento estatal define projetos e incentivos econômicos de alcance desigual, mediante programas incompletos e desintegrados de desenvolvimento regional" (Ab'Saber, 1999, p.8). Mas não se trata de julgar aspectos positivos ou negativos dessa dependência pública dos municípios da região, mas de analisar o que este perfil significa em termos de suas relações com a dinâmica da população, sobretudo a migração. Portanto, veremos a seguir uma caracterização do perfil recente das dinâmicas migratórias dessa região que, para todos os efeitos, mantém suas características de baixo dinamismo econômico e de estiagens prolongadas.

\section{CARACTERÍSTICAS DA MIGRAÇÃO NO SEMIÁRIDO}

Um dos aspectos demográficos mais evidentes e fundamentais para uma primeira aproximação é o perfil etário por sexo. A população do semiárido setentrional que era de 9,1 milhões em 1970 apresentou uma variação de 55\% até 2010 e atingiu 14,1 milhões. A particularidade da dinâmica demográfica dessa região contribuiu para que com ritmo de crescimento menor, a região se tornasse cada vez mais envelhecida do que o Nordeste como um todo, pois a proporção de idosos no semiárido passou de 3,6\% em 1970 para 8,2\% em 2010, enquanto que para o Nordeste essas proporções são de 3,2\% e 7,2\%, respectivamente. Ao mesmo tempo, a região apresenta uma proporção de jovens maior que o Nordeste como um todo, com $27 \%$ da população entre 0 e 14 anos. 


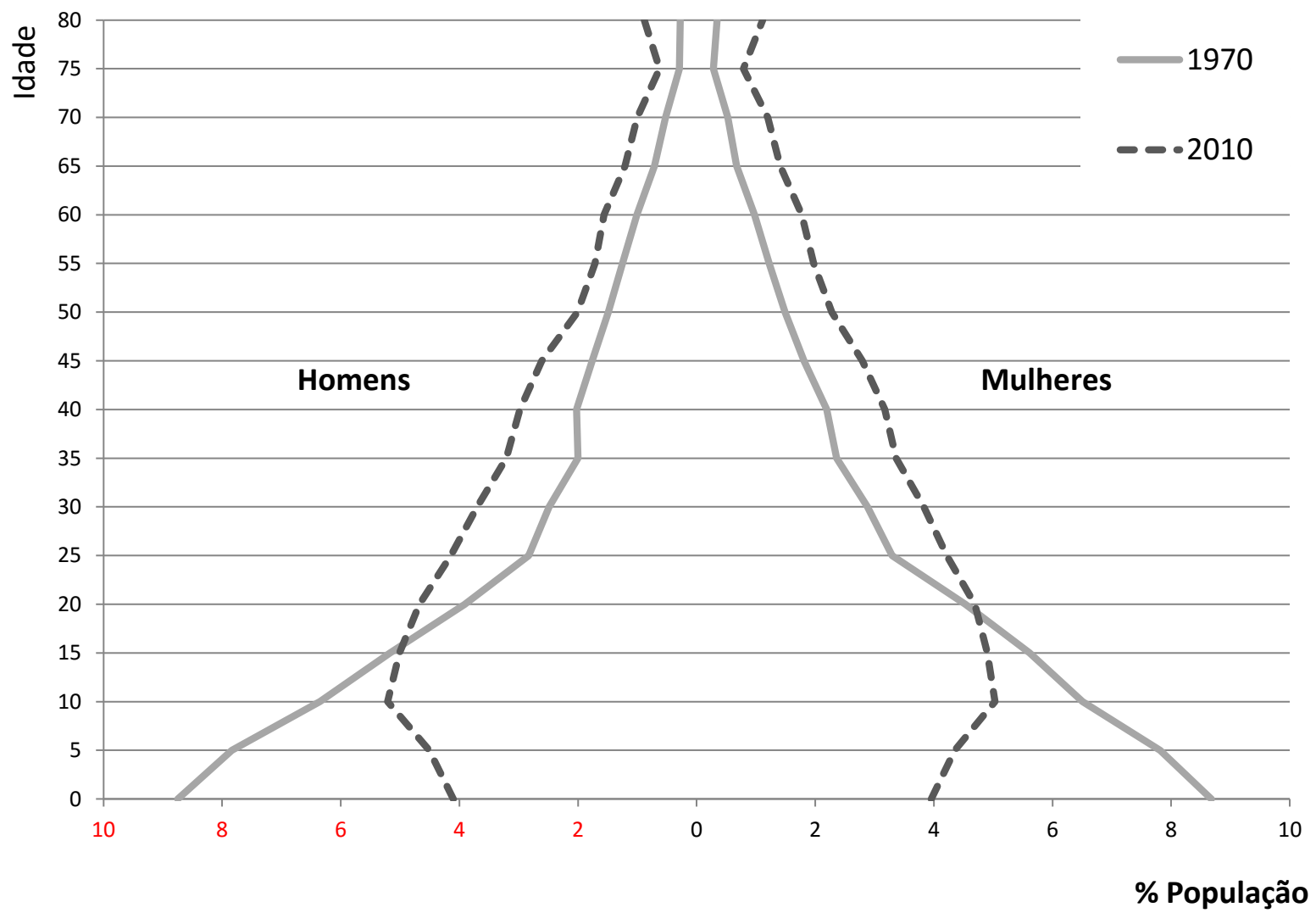

FIGURA 4 - Pirâmide etária da população do semiárido setentrional, 1970 e 2010 Fonte: IBGE, Censos Demográficos 1970 e 2010

Parte desta situação poderia ser explicada pela emigração ocorrida na região em meados do século passado, fato que pode ser presumido pela estrutura etária da população com marcada redução da participação da população nos grupos de idade adultas jovens, principalmente a partir dos 25 anos (ver FIG. 3). As análises que buscam explicar a emigração costumam associa-las à escassez de recursos hídricos, ou aos períodos cíclicos de estiagem que assolam a região. Entretanto, "existe considerável desacordo sobre a relevância da mudança ambiental para a migração" (Hogan, 2005, p.325), pois é sempre complexa a análise dos motivos da migração quando se questiona apenas os migrantes sobreviventes ao processo migratório.

Neste sentido, os dados disponíveis para a análise da migração devem ser tomados com cautela, pois consideram apenas os "sobreviventes" tanto em termos da mortalidade quando das eventuais reemigrações e até mesmo do retorno migratório à sua região de origem (Cf. Martine, 1980). Portanto, até que sejam investigados de maneira longitudinal, ou seja, em pesquisas específicas que visem acompanhar uma coorte de indivíduos acompanhando suas histórias migratórias, dificilmente será possível entender com tanta precisão as motivações e características psicossociais envolvidas nos fluxos migratórios.

Por outro lado, os dados censitários permitem realizar uma aproximação importante no que se refere às principais características dos migrantes e, com isso, analisar um amplo conjunto de 
informações socioeconômicas relacionadas aos processos sociais envolvidos. E no caso do Censo Demográfico 2010 é possível identificar a existência de benefícios provenientes de Programas de Transferência de Renda, como o PBF. Além do mais, o Censo Demográfico permite análises para cada um dos municípios brasileiros e que são comparáveis em termos temporais e espaciais.

TABELA 1 - Migrantes, Saldo Migratório e Taxa Líquida de Migração, segundo Unidades da Federação e subdivisões do Semiárido Setentrional e Demais municípios, 2005/2010

\begin{tabular}{|c|c|c|c|c|c|c|c|c|}
\hline \multirow{2}{*}{$\begin{array}{l}\text { Unidade da } \\
\text { Federação }\end{array}$} & \multicolumn{2}{|c|}{ Imigrantes } & \multicolumn{2}{|c|}{ Emigrantes } & \multicolumn{2}{|c|}{ Saldo Migratório } & \multicolumn{2}{|c|}{ TLM } \\
\hline & $\begin{array}{c}\text { Semiárido } \\
\text { Setentrional }\end{array}$ & Demais NE & $\begin{array}{c}\text { Semiárido } \\
\text { Setentrional }\end{array}$ & Demais NE & $\begin{array}{c}\text { Semiárido } \\
\text { Setentrional }\end{array}$ & Demais NE & $\begin{array}{c}\text { Semiárido } \\
\text { Setentrional }\end{array}$ & Demais NE \\
\hline$\overline{\text { Piaui }}$ & 23.559 & 50.056 & 51.195 & 92.842 & -27.636 & -42.787 & $-2,65$ & $-2,06$ \\
\hline Ceara & 66.950 & 45.422 & 119.162 & 62.060 & -52.212 & -16.637 & $-1,11$ & $-0,45$ \\
\hline Rio Grande do Norte & 29.947 & 37.781 & 26.325 & 27.692 & 3.622 & 10.089 & 0,21 & 0,72 \\
\hline Paraiba & 50.765 & 45.263 & 79.911 & 45.610 & -29.147 & -346 & $-1,39$ & $-0,02$ \\
\hline Pernambuco & 80.896 & 67.602 & 105.896 & 117.688 & -25.000 & -50.086 & $-0,68$ & $-0,97$ \\
\hline Alagoas & 17.098 & 36.491 & 42.310 & 87.996 & -25.213 & -51.504 & $-2,80$ & $-2,32$ \\
\hline TOTAL & 269.214 & 282.615 & 424.799 & 433.887 & -155.585 & -151.272 & $-1,10$ & $-0,93$ \\
\hline
\end{tabular}

Fonte: IBGE, Censo Demográfico 2010

Considerando os migrantes interestaduais classificados segundo a subdivisão do semiárido, a TAB. 1 permite perceber algumas características importantes da migração quando analisamos separadamente os municípios localizados no semiárido setentrional e os demais municípios das seis Unidades da Federação que os contém. O primeiro destaque que deve ser feito é a situação peculiar do Rio Grande do Norte enquanto a única UF que apresenta saldos migratórios positivos tanto no semiárido como fora dele. Nessa UF o saldo migratório do semiárido corresponde a $26,4 \%$ do saldo total da UF, indicando que não é o semiárido a região que absorve mais população. Como apontado por Nascimento e Ojima (2012), é a Capital (Natal) e seu entorno imediato que concentram a maior parte dos saldos migratórios da UF, sobretudo aqueles com origem em Unidades da Federação fora da região Nordeste.

Para as demais UFs aqui analisadas, há uma manutenção dos saldos migratórios negativos, mas a analise recortada pelo semiárido permite perceber diferenças que merecem atenção e análises futuras mais detalhadas. Os casos da Paraíba e do Ceará se destacam por apresentarem uma participação predominante do semiárido nos saldos negativos. Na Paraíba praticamente todo o saldo negativo é decorrente da região do semiárido enquanto que no Ceará o semiárido representa pouco mais de $75 \%$ do saldo negativo da UF. Como podemos perceber no FIG 4, estas duas UFs se destacam muito dos demais o que pode estar relacionado em parte pela extensão do semiárido na área total da UF, embora isso se aplique a praticamente todos as demais UFs, como foi ilustrado na FIG 1. 


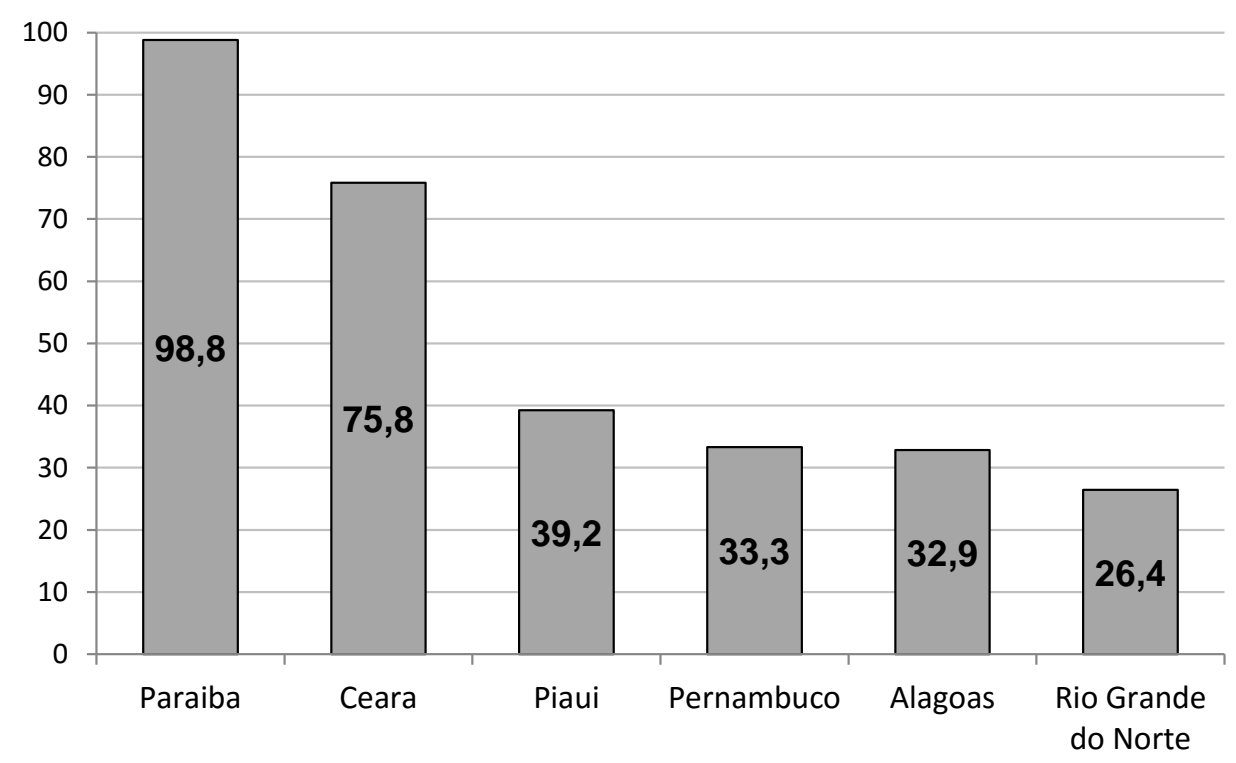

\section{FIGURA 5 - Participação relativa do saldo migratório do semiárido no saldo migratório total das Unidades da Federação, 2005/2010 \\ Fonte: IBGE, Censo Demográfico 2010}

Considerando a Taxa Líquida de Migração (TLM), ou seja, o impacto do saldo migratório sobre a população total das duas sub-regiões, podemos dizer que, em termos gerais, nas seis UFs analisadas as diferenças são pequenas entre o semiárido e o resto dos municípios. Com base neste indicador migratório, podemos dizer que entre as UFs onde a migração tem maior impacto sobre a população do semiárido estão Piauí, Ceará, Alagoas e Paraíba, sendo que neste último, a TLM é coerente com a informação analisada a partir da FIG 5, pois a migração praticamente não tem impacto entre o conjunto dos municípios fora do semiárido dessa UF. Por outro lado, nas UFs onde a migração tem maior impacto sobre a população fora do semiárido estão o Pernambuco e o Rio Grande do Norte, sendo que no último, o impacto é positivo, como pode ser visto na FIG 6. 


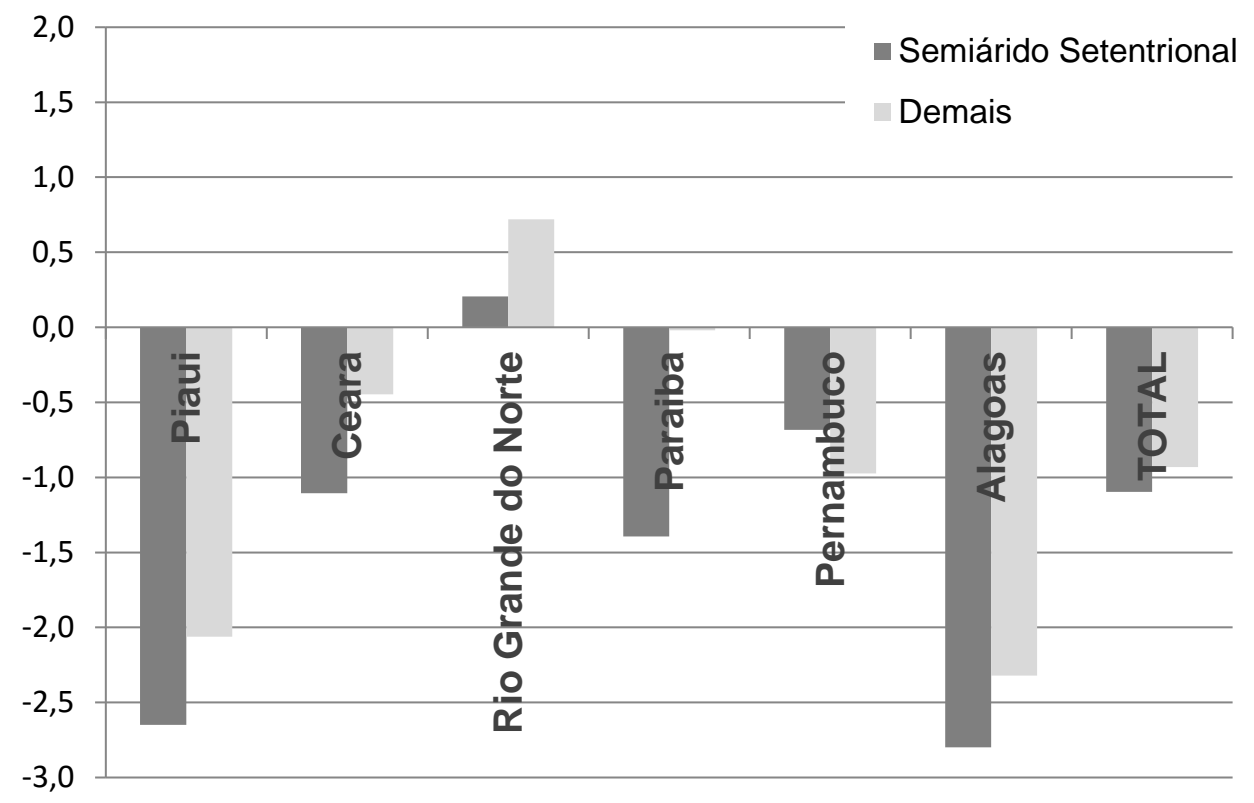

FIGURA 6 - Taxa Líquida de Migração segundo Unidades da Federação e subdivisões do Semiárido Setentrional e Demais municípios, 2005/2010

Fonte: IBGE, Censo Demográfico 2010

São muitos os fatores que poderiam explicar estes diferenciais por UFs, mas o que podemos destacar nessa análise mais geral é que o semiárido não foi em sua totalidade a região que mais expulsou a população no último quinquênio da década passada. O peso relativo do saldo migratório negativo observado no Piauí, Pernambuco e Alagoas (FIG 6) deixa claro que as dinâmicas migratórias são distintas em cada UF. Além disso, cabe destacar que a percepção estereotipada da fuga das secas do sertanejo também é outro elemento que merece ser investigado com mais detalhe, pois metade do saldo migratório negativo acumulado nas seis UFs analisadas é gerada nos municípios do que não fazem parte do semiárido setentrional.

\section{A MIGRAÇÃO DE RETORNO E OS IMPACTOS DAS POLÍTICAS SOCIAIS NOS FLUXOS MIGRATÓRIOS}

Recentemente, um dos aspectos que assume cada vez maior relevância é a migração de retorno. Como apontado por Ribeiro, Carvalho e Wong (1996), nessa categoria encontram-se os naturais de uma determinada região que após uma (ou mais de uma) etapa migratória retorna à sua região de origem, tanto como consequência do êxito no seu projeto migratório, como em um retorno compulsório decorrente do fracasso de seu projeto. Em qualquer um dos casos, as analises realizadas a partir de dados censitários não permite analisar as causas do retorno, mas a partir de algumas características destes migrantes retornados, seria possível 
construir algumas hipóteses, sobretudo quando relacionamos esse processo à ampliação da cobertura de políticas de transferência de renda.

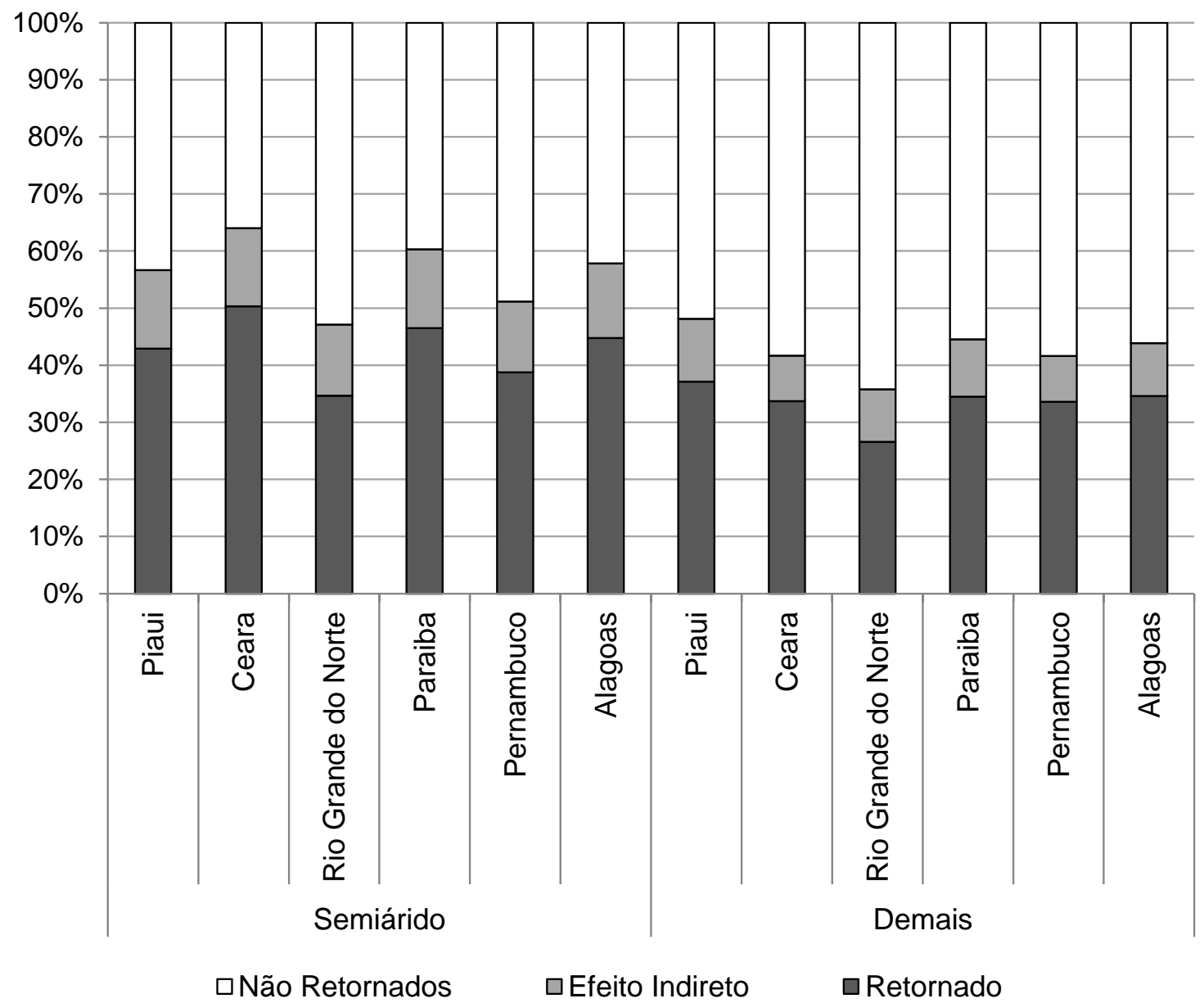

FIGURA 7 - Participação relativa dos retornados, efeitos indiretos do retorno e migrantes diretos segundo Unidades da Federação e subdivisões do Semiárido Setentrional e Demais municípios, 2005/2010

Fonte: IBGE, Censo Demográfico 2010

A retorno migratório no Brasil, mensurado pelos naturais da UF onde residiam na ocasião do Censo Demográfico 2010 e que viviam em outra UF a exatos cinco anos antes, somavam cerca de 1 milhão de pessoas em 2010. Esse montante representava 21,5\% de todos os migrantes do país nesse ano. Mas é na região Nordeste do país que a migração de retorno apresenta as maiores participações em relação ao total de movimentos migratórios. Por exemplo, na Paraíba e Ceará o retorno migratório era responsável por mais de $40 \%$ de todos os imigrantes destas UFs. Considerando o semiárido, novamente são as UFs do Ceará e Paraíba onde os migrantes de retorno apresentam a maior participação no total de imigrantes. Na comparação a partir da FIG 7, destaca-se também o fato de que os migrantes de retorno são mais representativos no semiárido do que nos demais municípios em todas as UFs. 
Quando separamos os migrantes segundo sua região de residência atual, considerando o recorte do semiárido setentrional, percebemos que nessa região a importância do retorno migratório é maior do que fora do semiárido. Isso significa dizer que na região fora do semiárido, há um contingente mais representativo de imigrantes diretos, ou seja, de pessoas que não são nascidas nas UFs para onde migraram. Entretanto, cabe destacar que parte significativa destes migrantes diretos pode ter estreita relação com o retorno migratório. Como destacado por Ribeiro, Carvalho e Wong (1996), por exemplo, uma parcela dos imigrantes que nasceram em UFs diferentes daquelas onde residem atualmente podem estar associados à migração de um retornado daquele domicílio. Assim, quando o migrante passa alguns anos fora de sua UF natal e depois retorna casado e com filhos, pode ocorrer que estes filhos e até o cônjuge sejam naturais de UF diferente daquela do retornado. Nesse caso, estes filhos e cônjuges entrariam na contabilidade dos migrantes diretos, embora se possa supor que esse movimento migratório está fortemente associado ao retorno do chefe do domicílio.

Baseado nessa hipótese, estimamos este Efeito Indireto da migração de retorno (ver FIG 7), considerando todo o imigrante direto residente no mesmo domicílio em que o responsável pelo domicílio ou seu cônjuge fossem retornados. Haveria outras possibilidades de estimar este efeito indireto considerando, por exemplo, apenas os domicílios onde todos os membros fossem migrantes ou ainda apenas os migrantes que tivessem relação de filhos ou netos dos responsáveis pelo domicílio. Enfim, esta foi uma opção metodológica assumida aqui e reconhecemos o leque de possibilidades para entender estes efeitos indiretos.

Portanto, considerando o pressuposto adotado neste trabalho, aqueles que antes eram contabilizados como imigrantes diretos passariam a ser considerados efeitos indiretos da imigração de retorno caso vivessem no mesmo domicílio no qual o responsável pelo domicílio ou seu cônjuge fossem migrantes nascidos naquela UF. Podemos perceber, assim, que o retorno migratório considerando o seu efeito indireto torna-se mais expressivo ainda no semiárido. No Ceará, por exemplo, o peso relativo do imigrante de retorno aumentaria caso considerarmos o seu efeito indireto, pois chegaria a quase $65 \%$ de todos os imigrantes interestaduais para a sua porção semiárida. Fato que se repete em todas as demais UFs analisadas aqui e indicam haver um componente migratório familiar muito importante nesses contextos.

Com isso podemos refletir sobre a importância do contexto domiciliar (enquanto aproximação de família) no que se refere às características dos migrantes, particularmente entre os retornados ao semiárido. Afinal, quando estamos tratando das migrações para o semiárido 
setentrional, estamos nos referindo majoritariamente aos retornados e seus efeitos indiretos, assim, as etapas migratórias e os ciclos de vida dos migrantes apresentam-se como recursos metodológicos para refletir para além dos locais de destino e origem da migração (Cf. Peres, 2014). Neste sentido, destaca-se aqui a situação do Rio Grande do Norte, pois entre as seis UFs que compreendem o semiárido setentrional é a que tem menor participação dos retornados e de efeitos indiretos, embora mesmo assim esses migrantes representem quase $50 \%$ do total de movimentos para o semiárido setentrional e $35 \%$ na sua porção fora do semiárido.

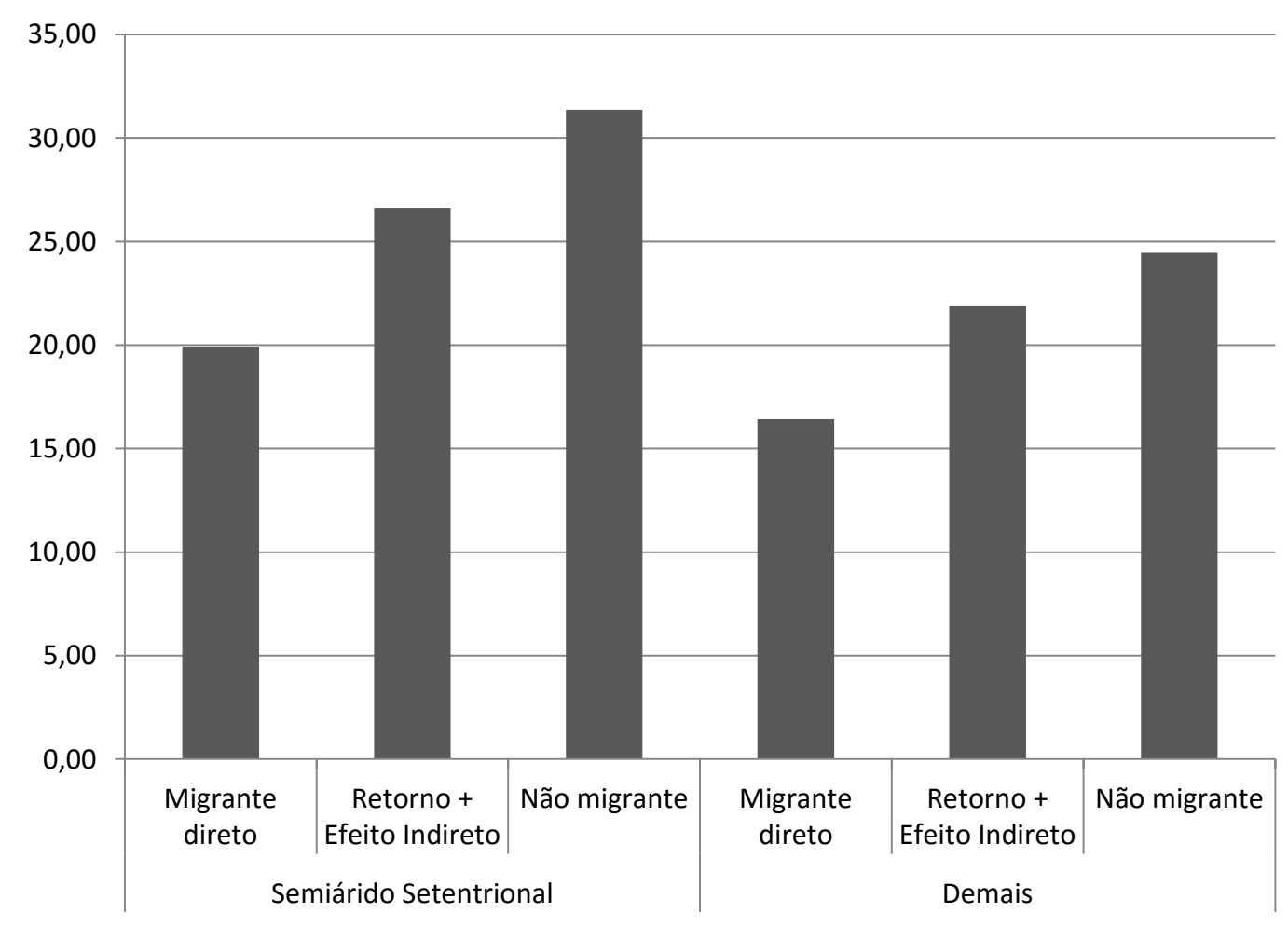

FIGURA 8 - Proporção de pessoas em domicílios que recebem benefícios de programas sociais segundo condição migratória e subdivisões do Semiárido Setentrional e Demais municípios, 2005/2010

Fonte: IBGE, Censo Demográfico 2010

O que podemos perceber na FIG 8, a partir dos dados do Censo Demográfico 2010 - que busca a informação se a pessoa recebe benefícios de aposentadoria ou pensão do INSS, Programa Bolsa Família ou PETI e Outros - é que há uma maior participação desses programas entre os indivíduos retornados e seus efeitos indiretos se comparado com os migrantes diretos. Assim, pode-se supor que possa haver uma tendência de incentivo ao retorno migratório quando beneficiário de programas sociais do que quando a migração é direta.

Quando comparamos a subdivisão do semiárido e demais municípios destas UFs, percebemos que há uma maior incidência dos programas sociais no primeiro caso. Como era de se esperar, 
há uma tendência de maior presença de programas sociais entre os indivíduos residentes nessa região. Entretanto, os diferenciais são pequenos e seria necessária uma análise mais detalhada acerca dessas categorias. Entretanto, o que podemos ter claro é que no semiárido setentrional o PBF atinge mais pessoas do que o benefício das aposentadorias e pensões quando estamos observando os migrantes diretos ou retornados e seus efeitos indiretos. Fato que não ocorre nos demais municípios fora do semiárido nas UFs que a compõe. Assim, embora o valor do benefício seja menor, ele participa em maior extensão nas receitas dos domicílios de migrantes.

\section{CONSIDERAÇÕES FINAIS}

Embora a opinião pública considere o PBF como uma política pró-natalista, o fato é que passados dez anos de implementação deste desenho de política de transferência de renda, as taxas de fecundidade do país apresentaram declínio regular em todas as regiões do país e em todos os estratos de renda, passando de 2,36 para 1,82 filhos por mulher entre 2000 e 2010 e particularmente na região Nordeste, que apresentou redução de 2,69 para 1,92 (Cf. DataSUS, 2013). Enfim, os estudos já desenvolvidos com esse recorte mostram que o efeito prónatalista é questionável, pois retrata muito mais os diferenciais de fecundidade anteriores ao recebimento dos programas (Cf. Alves; Cavenaghi, 2009). Por outro lado, o panorama analisado neste artigo no que se refere à imigração, particularmente o retorno migratório, aparenta ter ligação com os benefícios recebidos pelos programas de transferência de renda.

O benefício de aposentadoria tem um papel importante no retorno migratório (Cf. Campos; Barbieri; Carvalho, 2008) e, pelo menos preliminarmente, pudemos perceber nos demais programas de transferência de renda algum impacto sobre a imigração, sobretudo nas regiões onde a dinâmica econômica depende com maior intensidade do Estado. Nesse sentido, a associação direta entre o agravamento das estiagens no semiárido setentrional e um suposto novo fluxo de emigração em direção aos grandes centros pode ser questionado. Como pudemos perceber, o saldo migratório negativo no semiárido é praticamente o mesmo encontrado na região fora do semiárido. Portanto, condições sociais de manutenção e até de atração populacional devem ser analisados com mais detalhes para entender as transformações recentes nas migrações brasileiras.

Enfim, nessa breve análise descritiva desenvolvida no artigo pudemos identificar algumas das características da migração no semiárido setentrional a partir de uma análise intrarregional, enfatizando a questão da migração de retorno e das políticas sociais. Evidentemente que há ainda muito a ser investigado na região, mas considerando a ausência de estudos com essa 
perspectiva na região, considera-se que essa seja o início de uma agenda de pesquisa que deverá apontar para evidências importantes para modelos explicativos mais frutíferos para a região. Uma delas seria o fato de que os fatores de repulsão coexistem aos fatores de atração mesmo em contextos nos quais aparentemente prevalece o primeiro. Isso se deve ao fato de que considerar os fatores de atração dos lugares de destino em contraposição aos fatores de expulsão dos lugares de origem dos fluxos migratórios obscurece a possibilidade de entender elementos concorrentes que possam existir, por exemplo, o caso das políticas sociais no semiárido setentrional.

Conforme apontado por alguns autores (Oliveira; Oliveira, 2011; Brito, 2009), há que se pensar em novas abordagens explicativas para entender a diversidade de tendências migratórios em curso. Entretanto, talvez não seja necessário buscar novas teorias, mas dar um olhar diferenciado para os recortes de análise e seus aspectos menos evidentes, pois podem estar nas entrelinhas os potenciais explicativos destas "novas" tendências.

\section{REFERÊNCIAS}

AB'SABER, A. N. "Sertões e sertanejos: uma geografia humana sofrida”. Estudos Avançados, IEA/USP, São Paulo, v. 13, n. 36, 1999, p. 7-59.

ALVES, J.E.D.; CAVENAGHI, S. Dinâmica demográfica e políticas de transferência de renda: O caso do Programa Bolsa Família no Recife. Revista Latinoamericana de Población. Ano 3, n. 4-5, 2009, p. 165-188.

BRITO, F. As migrações internas no -Brasil: um ensaio sobre os desafios teóricos recentes. Anais do VI Encontro Nacional sobre Migrações, Belo Horizonte: ABEP, 2009.

BRONZO, C. Território como categoria de análise e como unidade de intervenção nas políticas públicas. In: FAHEL, M; NEVES, J.A.B. Gestão e avaliação de políticas sociais no Brasil. Belo Horizonte: PUC Minas, 2007.

CAMPOS, M.B.; BARBIERI, A.F.; CARVALHO, J.A.M. Migração e Previdência Social no Brasil entre 1980 e 2000. In: Mudança populacional: aspectos relevantes para a Previdência - Brasília : MPS, SPPS, 2008.

CEDEPLAR - Centro de Desenvolvimento e Planejamento Regional de Minas Gerais (UFMG). Avaliação de Impacto do Programa Bolsa Família - Sumário Executivo, MDS, Brasília, outubro, 2007. 
DATASUS - Banco de dados do Sistema Único de Saúde. Indicadores e Dados Básicos, Brasil 2011. IDB-2011. Ministério da Saúde/SUS, 2011.

DRAIBE, S.M. A Política Brasileira de Combate à Pobreza. In: Velloso, J.P.R. (Coord.). O Brasil e o Mundo no Limiar do Novo Século. Rio de Janeiro: José Olympio, 1998.

DRAIBE, S.M. As Políticas Sociais Brasileiras: diagnósticos e perspectivas. In: Para a Década de 90: prioridades e perspectivas de políticas públicas - Políticas Sociais e Organização do Trabalho. Brasília: IPEA, 1989.

FURTADO, C. A operação Nordeste. Rio de Janeiro: Ministério da Educação e Cultura, Instituto Superior de Estudos Brasileiros, 1959.

HOGAN, D.J. Mobilidade populacional, sustentabilidade ambiental e vulnerabilidade social. Revista Brasileira de Estudos da População, São Paulo, v. 22, n. 2, p. 323-338, 2005.

IBGE - Instituto Brasileiro de Geografia e Estatística. Produto Interno Bruto dos Municípios 2011. Rio de Janeiro: IBGE, 2011.

IPEA - Instituto de Pesquisa Econômica Aplicada. O Brasil em 4 décadas. Brasília: IPEA, Texto para Discussão n. 1500. 2010.

MARTINE, G. Adaptação dos migrantes ou sobrevivência dos mais fortes? In: MOURA, H. (Org.). Migração interna: textos selecionados. Fortaleza: Banco do Nordeste do Brasil S.A., 1980.

MEDEIROS, M. A trajetória do walfare state no Brasil: papel redistributivo das políticas sociais dos anos 1930 aos anos 1990. Brasilia: IPEA. Texto para discussão n. 852, 2001.

NASCIMENTO, T.C.L.; OJIMA, R. Entre as idas e vindas potiguares: desenvolvimento regional e migrações no contexto do Rio Grande do Norte. Cadernos de Estudos Sociais, v. 27, p. 166-190, 2012.

OJIMA, R. Urbanização, Dinâmica Migratória e Sustentabilidade no Semiárido Nordestino: o papel das cidades no processo de adaptação ambiental. Cadernos Metrópole (PUCSP), v. 15, p. 35-54, 2013.

OJIMA, R.; MARTINE, G. Resgates sobre População e Ambiente: breve análise da dinâmica demográfica e a urbanização nos biomas brasileiros. Idéias - Revista do Instituto de Filosofia e Ciências Humanas da UNICAMP, v. 1, p. 55-70, 2012. 
OLIVEIRA, L.A.P.; OLIVEIRA, A.T.R. (Orgs.) Reflexões sobre os deslocamentos populacionais no Brasil. Série Estudos e Análises: Informação demográfica e socioeconômica. n.1. Rio de Janeiro: IBGE. 2011.

OLIVER, C. Retirement migration: paradoxes of ageing. New York/London: Routledge. 2008.

PERES, R.G. "O que importa é o que acontece com a sua família": um diálogo entre família e migração. Revista PerCursos. Florianópolis, v. 15, n.28, p. 146 - 165. jan./jun. 2014.

REGO, W.L.; PINZANI, A. Vozes do Bolsa Família: autonomia, dinheiro e cidadania. São Paulo: Ed. Da Unesp, 2013.

RIBEIRO, J.T.L. CARVALHO, J.A.M. WONG, L.R. Efeitos demográficos da migração de retorno: uma proposta metodológica. In: X Encontro Nacional de Estudos Populacionais, 1996. ABEP, 1996.

RIOS-NETO, E.L.G., MARTINE, G.; ALVES, J.E.D. Oportunidades perdidas e desafios críticos: a dinâmica demográfica brasileira e as políticas públicas. Demografia em Debate n. 3, Belo Horizonte: ABEP: UNFPA: CNPD, 2009.

SILVA, M.O.S.; YAZBEK, M.C.; GIOVANNI, G. A política social brasileira no século XXI: a prevalência dos programas de transferência de renda. 6.a ed. São Paulo: Cortez, 2012.

WEISSHEIMER, M.A. Bolsa família: avanços, limites e possibilidades do programa que está transformando a vida de milhões de famílias no Brasil. São Paulo: Ed. Fundação Perseu Abramo, 2010. 